\title{
Ancestral Peruvian ethnic fermented beverage "Chicha" based on purple corn (Zea mays L.): unraveling the health- relevant functional benefits
}

\author{
Diego Vargas-Yana ${ }^{1}$, Brigitte Aguilar-Morón ${ }^{1}$, Nelly Pezo-Torres ${ }^{1}$, Kalidas Shetty² and Lena Gálvez Ranilla ${ }^{1 *}$
}

\begin{abstract}
Chicha is a traditional ethnic corn-based fermented beverage with a profound cultural relevance in the Andean region, especially in Peru where it has been part of religious ceremonies since pre-Inca civilizations. Chicha de Guinapo is made with purple corn and is a typical beverage from the Peruvian region of Arequipa (South of Peru) where some local people still preserve its traditional process and use, but no investigation has been focused on the study of its potential health-relevant functional properties linking the historical perspectives. The current research was aimed at advancing the ethnic cultural relevance of this traditional beverage with an understanding of deep historical and ecological roots and further by evaluating the differences in the traditional processing of Chicha de Guiñapo from five geographical zones in Arequipa (Peru). Furthermore, to understand the potential health relevance, the influence on the total phenolic content (TPC), the total anthocyanin content (TAC), the antioxidant capacity, the in vitro inhibition of a-glucosidase and a-amylase relevant for hyperglycemia management, along with the physicochemical characteristics, were evaluated. No significant differences were observed in the physicochemical parameters, the antioxidant capacity, and the phenolic contents among the Chicha samples from different origins. However, all samples showed a remarkable in vitro inhibition of a-glucosidase and a-amylase with a significant influence of the geographical zone of origin that links historical usage and contemporary health benefits. The Z2 Chicha sample that followed the most traditional preparation had the highest values of TAC, in vitro antioxidant capacity, and anti-hyperglycemia-relevant a-glucosidase and a-amylase inhibitory activities. Results from the current study reveal that Chicha has an important health-relevant functional potential and that the preservation of the traditional historical and ethnic knowledge about its processing is critical for its validation for wider use across all communities.
\end{abstract}

Keywords: Chicha de Guiñapo, Peruvian purple corn, Phenolic compounds, Ethnic relevance, Health

\footnotetext{
* Correspondence: Igalvez@ucsm.edu.pe

'Laboratory of Research in Food Science, Universidad Catolica de Santa

Maria, Urb. San José s/n Umacollo, Arequipa, Peru

Full list of author information is available at the end of the article
}

(c) The Author(s). 2020 Open Access This article is licensed under a Creative Commons Attribution 4.0 International License, which permits use, sharing, adaptation, distribution and reproduction in any medium or format, as long as you give appropriate credit to the original author(s) and the source, provide a link to the Creative Commons licence, and indicate if changes were made. The images or other third party material in this article are included in the article's Creative Commons licence, unless indicated otherwise in a credit line to the material. If material is not included in the article's Creative Commons licence and your intended use is not permitted by statutory regulation or exceeds the permitted use, you will need to obtain permission directly from the copyright holder. To view a copy of this licence, visit http://creativecommons.org/licenses/by/4.0/. 


\section{Introduction}

The word "Chicha" is used to describe a great variety of traditional ethnic fermented beverages highly consumed along the Andean region in South America, and made from different plant sources especially from maize (Zea mays L.) and among other grains such as some Andean pseudo cereals like quinoa (Chenopodium quinoa) (see Additional file 1, A). The origin of the word comes from the indigenous Panamanian word "chibcha" which means "maize" [1]. It is known that Chicha has been consumed for more than a thousand years in the Andean region, before the arrival of the Europeans and even before the rise of the empire of the Incas $[2,3]$.

The Chicha beverage was consumed as an integral part of daily food consumption and was used in religious ceremonies as a tribute for the dead along several important pre-Inca Andean cultures or larger civilizations, especially during the period of the Chavin, Marcavalle, Churajon, and Tiwanaku cultures (Fig. 1). Even though no written records exist about these practices during the pre-Inca period, several archeological studies have revealed that some ceramic plates and vessels were used for drinking Chicha $[9,10]$.

The geographical spread of the empire of the Incas (thirteenth to sixteenth century) extended to the present-day countries of Peru, Ecuador, Chile, and Argentina allowing the spread of Chicha preparation and consumption throughout the Andean region (Fig. 1). This beverage was used both as part of daily diet of the Inca population and as an essential element during the political and religious ceremonies. In this period, Chicha was not only made from corn but also from a variety of food plants such as oca (Oxalis tuberosa), cassava (Manihot esculenta), and quinoa (Chenopodium quinoa) [2]. The great extension of the empire of the Incas allowed the incorporation of the traditional practices of pre-Inca civilizations, and inhabitants across the empire therefore adapted the production of Chicha according to their own traditions and culture [10].

The expression "Chicha de Jora" was used for the first time during the colonial time when Spanish people invaded the territory of the Incas (sixteenth to nineteenth century). Chicha de Jora is a fermented beverage made only from maize and has a wide variety of colors and flavors depending on the type of maize used for its processing. The term "Jora" refers to the use of a completely germinated corn kernel as a raw material for Chicha preparation. During this period, the "chicherias" (places where Chicha was prepared and sold), "pulperias" (taverns), and "picanterias" (traditional places where people gathered to eat, drink Chicha and talk about the events of the day) appeared for the first time [2]. Currently, some local restaurants have preserved the tradition of picanterias in certain regions of Peru.
The region of Arequipa is in the south west of Peru and has eight geographical provinces with a capital city also named Arequipa which is located at an average altitude of $2335 \mathrm{~m}$ above sea level (m.a.s.l.) close to the Southern Andean mountains (Fig. 2). Ethnically, people from Arequipa city are mainly "mestizos" descendants of the native Americans and Spanish population that settled down in this area in the sixteenth century. This ethnic background has shown a marked influence on several cultural and historical aspects of Arequipa including its local gastronomy that has incorporated Andean foods and ingredients derived from foods introduced by the Spanish. However, the consumption of Chicha has been maintained during the colonial time until now, and its method of preparation in principle has been preserved since the pre-Inca ancestral and historical period with some modifications across time and depending on the Andean location [10].

In Arequipa, the beverage is known as "Chicha de Güiñapo" and has become unique compared to Chicha from other regions of Peru due to the use of partially germinated purple corn (Güiñapo) as the main ingredient according to the oral tradition. This type of Chicha is produced by first germinating grains of local purple-black corn in a "poyo" (a rectangular stone container) which is covered with straws and watered for 15 days approximately. After this step, partially germinated kernels are sun-dried and then milled into a coarse flour (Fig. 3). This flour is subsequently boiled with water for some hours to be then filtered. The insoluble cake is used to feed poultry and the filtered liquid is fermented overnight using "concho" or the residues of Chicha from the previous day [2] (Fig. 4). Chicha de Güiñapo was the historical basis of the ethnic food culture and gastronomy of Arequipa until the nineteenth century and the beverage was even more important than food itself [3]. The migration of people from the Peruvian coastal cities such as Lima and Trujillo influenced the Chicha processing replacing for example the use of locally grown purple corn by more commercial purple corn varieties which give a different flavor and texture to the final beverage. Slowly, its name and indication as Chicha de Güiñapo was changed to Chicha de Jora and "chicherias" lost importance giving prevalence to "picanterias."

Currently, some places in Arequipa are trying to preserve the tradition of picanterias (where Chicha and typical food are prepared) and to reintroduce the name Chicha de Güiñapo specially for reinforcing the local cultural identity. Besides its use as a beverage, Chicha still has a deep cultural and religious meaning for native people from Andean locations in Arequipa. For example, in the present-day personal observations in the district 


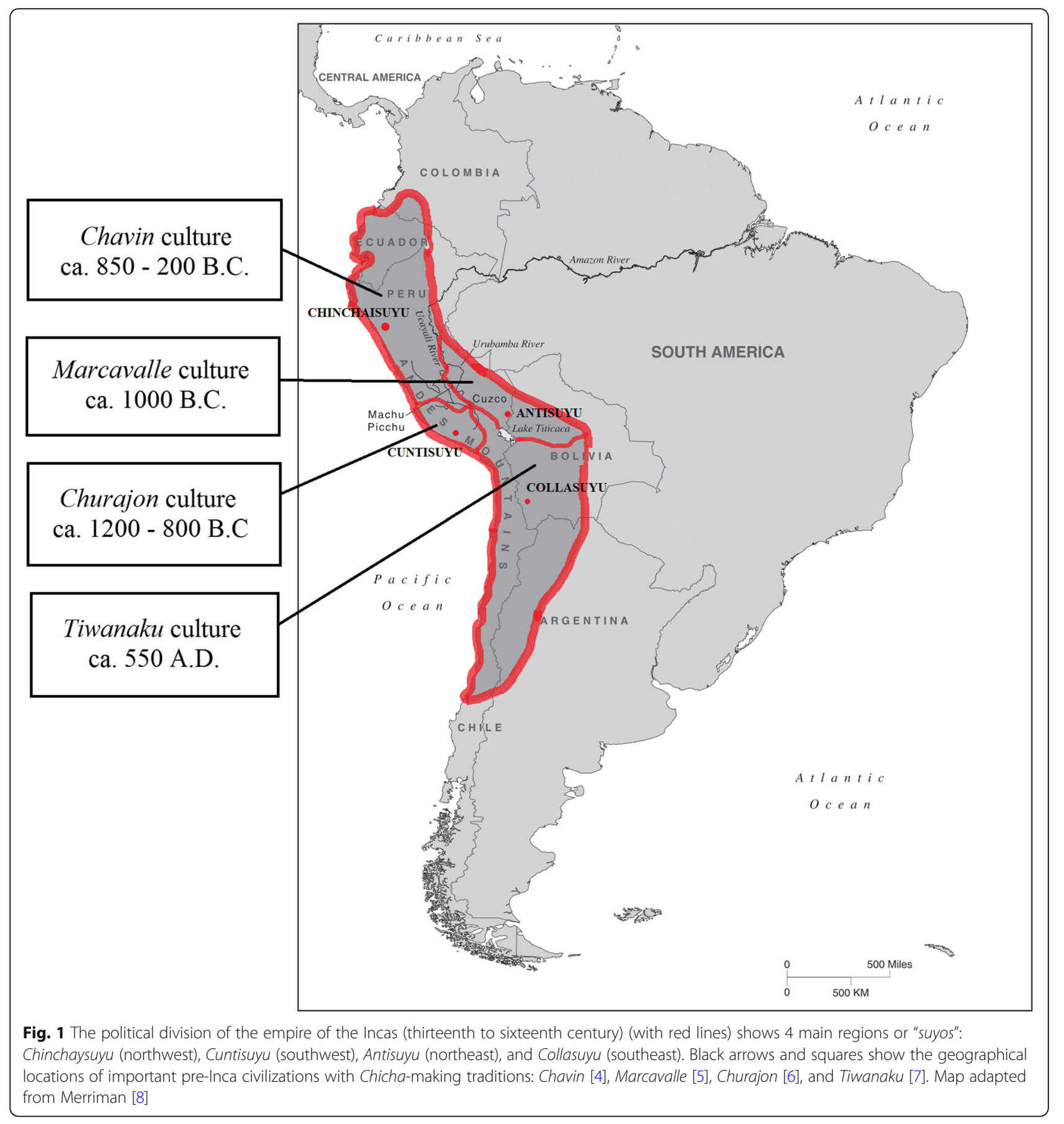

of Viraco (Castilla province in Arequipa) located at more than 3000 m.a.s.l, Chicha has been used as an offering together with flowers, coca (Erythroxylum coca) leaves, llama fat (pichihuira in the native quechua language), corn kernels, and cigars to give thanks to the "Pachamama" (mother earth in quechua) during the months of February and the winter solstice in June. The offering is done in a selected sacred place within the chacras (local farms) and is directed by a "chaman" (a sort of indigenous priest) in a massive fest with the objective to "pay the earth" or to give thanks to the earth for its generosity in the obtained harvest or the abundance of dairy and sheep cattle. After the chaman prayers in quechua language, all the offerings are buried, excepting Chicha which is poured on the ground. There is a strong belief among native farmers that if they do not give thanks to the earth in such ceremonies, next year's harvest and cattle will not be as fruitful as expected. Jennings [10] 


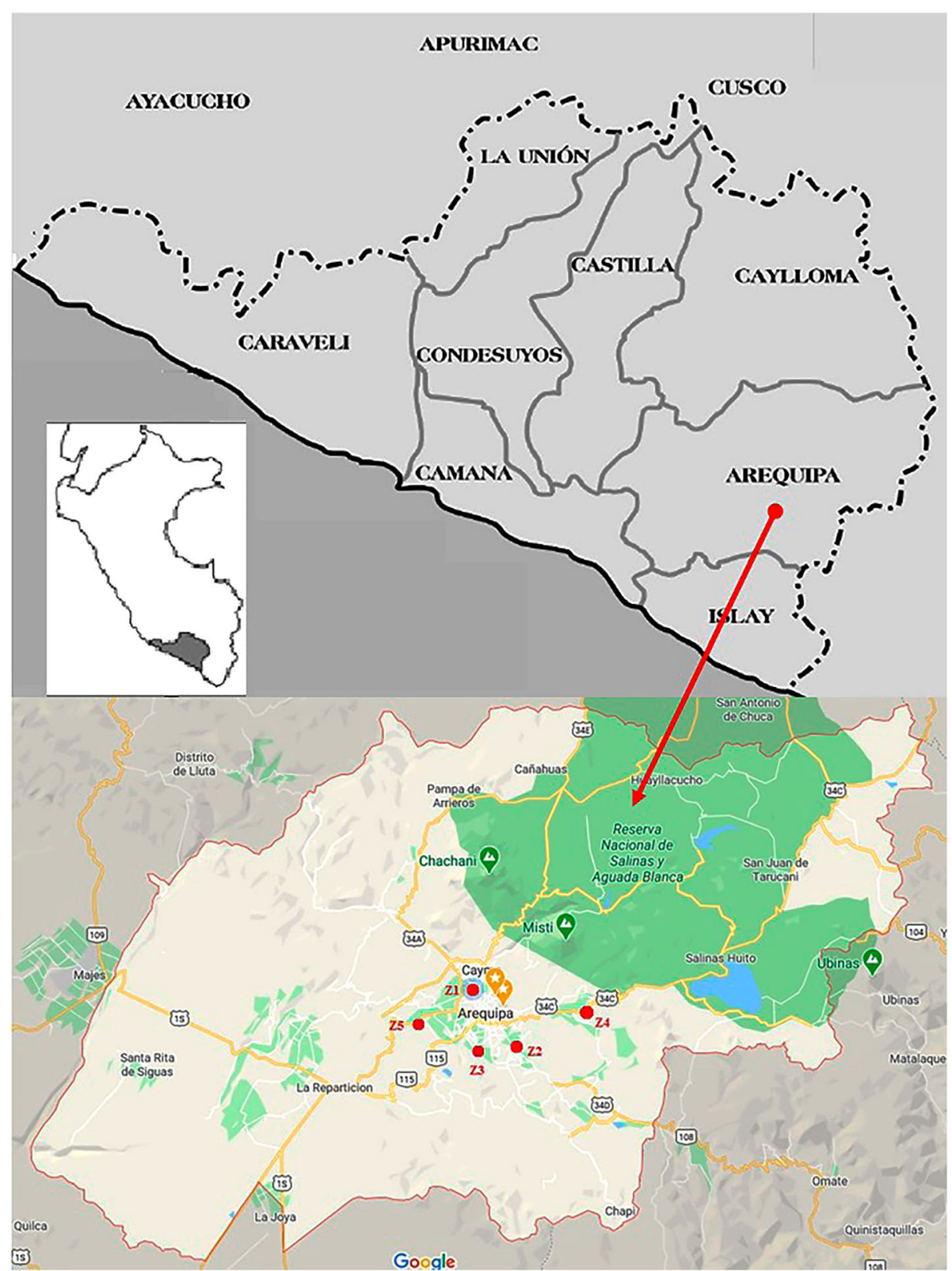

Fig. 2 Map of the Arequipa region. a Geographical location of Arequipa in relation to Peru. b Chicha sampling zones in the Arequipa province, denoted as Z1 (Arequipa), Z2 (Characato), Z3 (Socabaya), Z4 (Chiguata), and Z5 (Uchumayo). Adapted from [11-13]

has also described the use of Chicha in special events and feasts in other Andean regions in the country demonstrating that Chicha represents an important ethnic beverage in Peru.

Chicha de Jora which is more common in several regions of Peru differs from Chicha de Güiñapo in several processing parameters. Chicha de Güiñapo is made with partially germinated purple corn grains as stated above while Chicha de Jora is made with fully germinated purple corn kernels. Moreover, in the production of Chicha de Güiñapo, the total fermentation time is about $12 \mathrm{~h}$, whereas in Chicha de Jora, the fermentation time can go up to several days [7]. These differences may influence the sensorial characteristics of Chicha such as the flavor and the chemical and bioactive composition along with the microbiome profile after fermentation. Other variations of Chicha across the Andean region are associated with the use of different types of maize (purple corn, white or other colored corn kernels), the addition of spices or sugar, and the application of different fermentation times, among other factors [10, 14]. 
a)

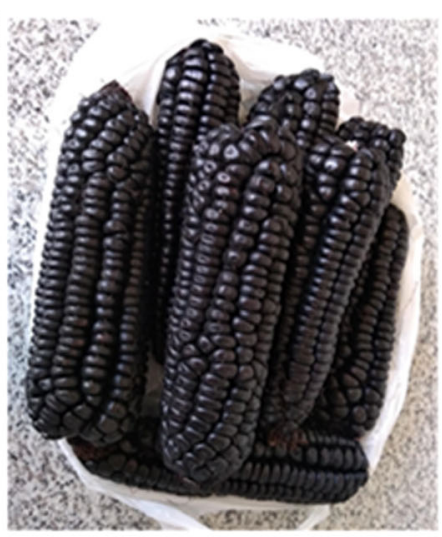

c)

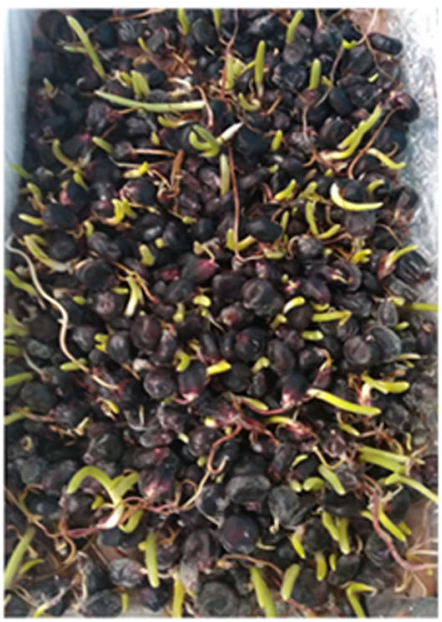

b)

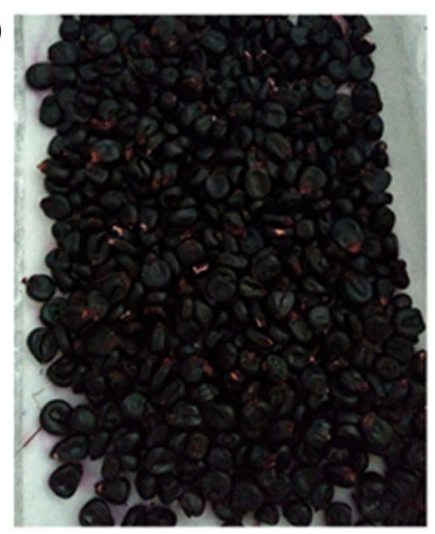

d)

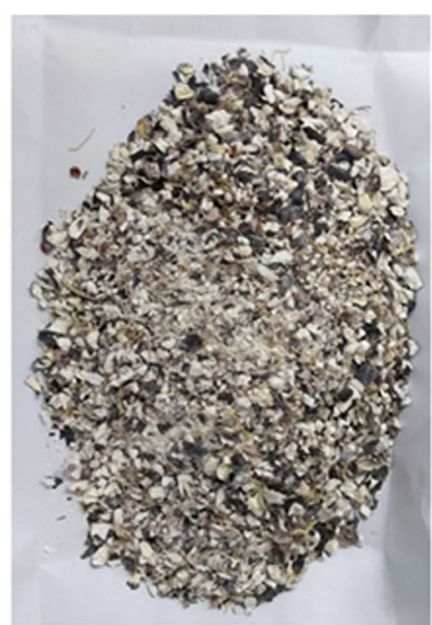

Fig. 3 Traditional processing of Chicha de Güiñapo (part 1): a mature purple corn ear, b purple corn kernels, c Partially germinated corn showing green seedlings, and $\mathbf{d}$ Milled germinated corn (Güiñapo)

Some types of Chicha from other countries or similar products derived from corn fermentation have been characterized mainly in terms of the microbiome composition [14-16]. However, the differences in current traditional processing of Chicha based on historical perspectives from several geographical areas in Peru and their association of the potential health-relevant bioactivity of Chicha based on fermentation of purple corn have not been investigated yet.

The current research was aimed at advancing the health relevance of this ethnic beverage treasure with deep historical relevance and perspectives by studying for the first time this purple corn-based fermented beverage from the Peruvian Andean region of Arequipa which has a well-known tradition in Chicha preparation based on deep historical knowledge. Main objectives were to document the traditional processing of Chicha de Güiñapo collected from different locations in Arequipa with historical knowledge and to evaluate its phenolic (total phenolics and anthocyanins) composition, the in vitro antioxidant capacity, and the potential in vitro inhibitory activity of $\alpha$-amylase and $\alpha$ glucosidase bioactivity relevant for hyperglycemia management. This study would help to understand the potential of Chicha as a functional ethnic beverage based on historical perspectives and to target the improvement of the traditional processing of Chicha relevant for its validation and preservation of its ethnic roots and historical value.

\section{Materials and methods}

Chicha samples

Chicha samples were collected from five geographical zones (districts) located in the southern Peruvian region of Arequipa (Arequipa province): Arequipa, Characato, Socabaya, Chiguata, and Uchumayo and coded as Z1, $\mathrm{Z} 2, \mathrm{Z3}, \mathrm{Z4}$, and Z5, respectively. The samples were collected once a week for three consecutive weeks (each sample was considered a replicate per zone of collection). During the collection, a survey was applied to owners of "picanterias" for documenting the likely differences in Chicha processing. 
a)

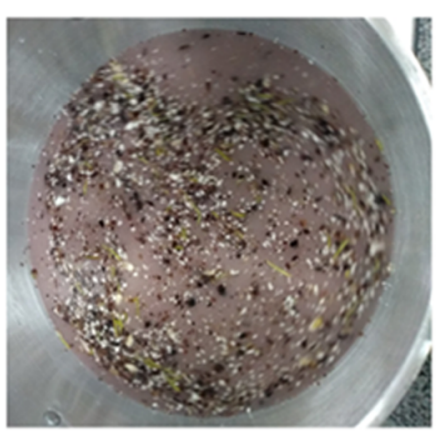

b)

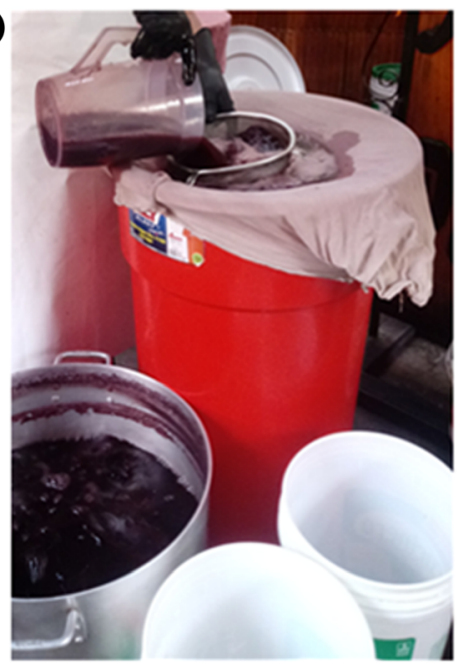

c)

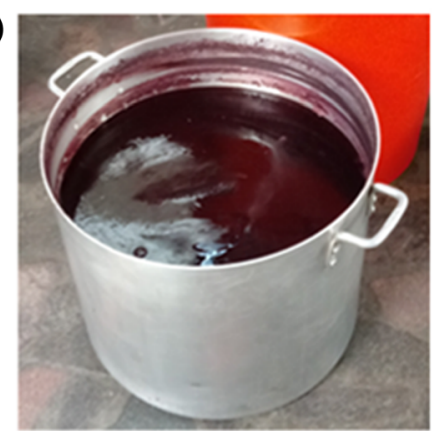

d)

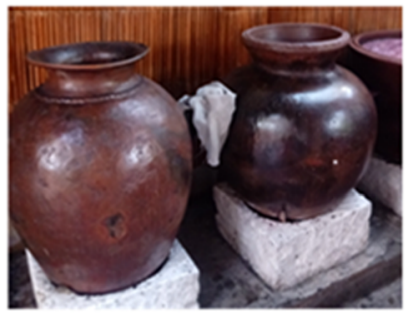

e)

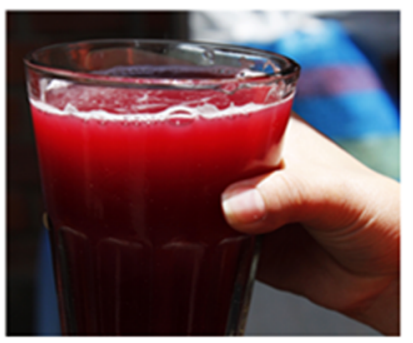

Fig. 4 Traditional processing of Chicha de Güiñapo (part 2): a boiling of Güiñapo, b filtration using a special cloth, c Chicha before fermentation, d fermentation in traditional ceramic pots (chombas), e Chicha de Güiñapo ready for consumption and served in a "caporal" (typical glass that mimics the shape of "Kero" which was a vessel used to drink Chicha in the Inca period)

Collected samples were transported in a refrigerated environment $\left(<10^{\circ} \mathrm{C}\right)$, and once in the laboratory samples were centrifuged at $2000 \mathrm{rpm}$ for $10 \mathrm{~min}$, and supernatants were degasified by vortex at $1200 \mathrm{rpm}$ for $5 \mathrm{~min}$ and then stored at $-20{ }^{\circ} \mathrm{C}$ until analysis.

\section{Enzymes}

$\alpha$-Glucosidase from Saccharomyces cerevisiae (EC 3.2.1.20) and $\alpha$-amylase (EC 3.2.1.1) from porcine pancreas were purchased from Sigma Chemical Co. (St. Louis, MO, USA).

\section{Physicochemical analyses}

The $\mathrm{pH}$ was determined using a $\mathrm{pH}$ meter. Soluble solids were determined using a refractometer at $20^{\circ} \mathrm{C}$. The alcohol content was determined as a percentage of ethanol according to the AOAC 935.19 method [17]. Titratable acidity (TA) was expressed as milligrams of lactic acid per $100 \mathrm{~mL}$ of Chicha according to the AOAC 942.15 method [17].

\section{Total phenolic content (TPC)}

The total phenolic content was determined by a modified Folin-Ciocalteu method based on the Singleton and Rossi method [18]. The total phenolic content was expressed as milligrams of gallic acid equivalents (GAE) per $100 \mathrm{~mL}$ of Chicha.

\section{Total monomeric anthocyanin content (TMA)}

The total monomeric anthocyanin content was determined by the differential $\mathrm{pH}$ method [19]. The results were expressed as milligrams of cyanidin-3-glucoside equivalents (C3G) per liter of Chicha.

\section{Ultra-high performance liquid chromatography (UHPLC) analysis of total anthocyanin content (TAC)}

The Chicha samples were centrifuged at $2000 \mathrm{rpm}$ for 5 min and a $2-\mathrm{mL}$ aliquot was vacuum evaporated at $40^{\circ} \mathrm{C}$ until dryness and resuspended in $1 \mathrm{~mL}$ of acidified water $(0.01 \% \mathrm{HCl})$. The concentrated samples were then purified in a Strata solid phase extraction C18-E column (55 $\mu \mathrm{m}, 70 \mathrm{~A}^{\circ}$ ) (Phenomenex Inc., Torrance, CA., USA) 
previously pre-conditioned using 2 volumes of methanol (Sigma Chemical Co., St. Louis, MO, USA) followed by 2 volumes of acidified water. Samples were then eluted with acidified methanol $(0.01 \% \mathrm{HCl})$, vacuum evaporated until dryness at $40^{\circ} \mathrm{C}$, and resuspended in $1 \mathrm{~mL}$ of acidified water [20].

Purified samples were filtered with a polyvinyldiene difluoride filter (PVDF, $0.22 \mu \mathrm{m}$ ), and $5 \mu \mathrm{L}$ was injected in an UltiMate 3000 RS UHPLC system (Thermo Fisher Scientific, Waltham, MA, USA), using an UltiMate 3000 RS quaternary pump and autosampler, a Vanquish diode array detection system, and controlled by the Chromeleon v7.2 SR4 software (Thermo Fisher Scientific). The anthocyanins were separated using a Kinetex C18 analytical column $(100 \times 2.1 \mathrm{~mm}$ i.d., $1.7 \mu \mathrm{m}$ particle size; Phenomenex) protected with a Kinetex guard column (5 $\times 2.1 \mathrm{~mm}$ i.d., $1.7 \mu \mathrm{m}$ particle size; Phenomenex). The sample vial tray was set at $5{ }^{\circ} \mathrm{C}$, and a flow rate of 0.2 $\mathrm{mL} / \mathrm{min}$ and a column temperature of $30^{\circ} \mathrm{C}$ were applied. The solvents used for gradient elution were (A) $0.1 \%$ formic acid ( $\mathrm{pH} 2.5$ ) and (B) 100\% acetonitrile. Initial conditions were 98\% (A) and 2\% (B), and the following gradient of solvent (B) was used: $2 \%$ for $2 \mathrm{~min}$, then increased to $15 \%$ in $1 \mathrm{~min}$ and to $45 \%$ over the next $6 \mathrm{~min}$, then increased to $98 \%$ over $1 \mathrm{~min}$ and maintained for $3 \mathrm{~min}$, and finally set to initial conditions in $4 \mathrm{~min}$ with a re-equilibration time of $3 \mathrm{~min}$ (total run time of $20 \mathrm{~min}$ ). The detection system was run from 200 to 600 $\mathrm{nm}$, and the quantification was done at $525 \mathrm{~nm}$. The sum of the areas of peaks detected at $525 \mathrm{~nm}$ was reported as TAC and expressed in milligrams of cyanidin chloride aglycone per liter (mg CC/L) using a calibration curve of this standard (Sigma Chemical Co., St. Louis, MO, USA $)$ diluted in acidified methanol $(0.5 \%$ acetic acid).

\section{Total antioxidant activity}

Total antioxidant activity was measured using two different methods: the 2,2-diphenyl-1-pycrilhidrazyl (DPPH) and the 2,2'-azino-bis(3-ethylbenzthiazoline-6-sulphonic acid) (ABTS+) free radical scavenging assays according to a modified method by Pérez-Jiménez [21].

The percentages of inhibitory activity obtained from the DPPH and ABTS radical scavenging assays were calculated and results were expressed as micromole of Trolox equivalents (TE) per $100 \mathrm{~mL}$ of Chicha using a curve of Trolox standard (100 to $900 \mu \mathrm{M})$ for both methods.

\section{$a-G l u c o s i d a s e$ and $a$-amylase inhibition assays}

The $\alpha$-glucosidase and $\alpha$-amylase inhibitory activities were determined using modified assay methods [22, 23]. The results were expressed as percentage of inhibition at different phenolic contents (GAE/mL).

\section{Statistical analysis}

All data were analyzed using the one-way analysis of variance (ANOVA) or the Kruskal-Wallis test when needed, following with the Tukey's test $(p<0.05)$ for multiple comparisons. The StatGraphics Centurion XVI software (Statgraphics Technologies, Inc., The Plains, Virginia) was used.

\section{Results and discussion}

\section{Traditional Chicha processing}

Figure 2 shows the geographical locations of picanterias (traditional restaurants) where Chicha de Güiñapo was sampled. A total of five zones corresponding to different districts (Z1:Arequipa, Z2:Characato, Z3:Socabaya, Z4: Chiguata, and Z5:Uchumayo) located in the province of Arequipa were selected based on the historical perspectives and ethnic antiquity of "picanterias" and because such places coincide with the location of pre-colonial "curacazgos" (local governments or provinces during the period of the empire of the Incas) where Chicha was likely prepared according to some historical records [6].

Table 1 summarizes the results of the surveys applied to owners of the five selected picanterias showing the different procedures for elaborating Chicha de Güiñapo. One of the most important difference is the type of raw material used. Chicha beverages from Arequipa and Characato districts ( $\mathrm{Z} 1$ and Z2, respectively) are made with Guiñapo (partially germinated and milled purple corn kernel) elaborated with the purple corn cultivated in the farms located in the same districts; therefore, people in such picanterias elaborate their own Guiñapo. In addition, they still use the traditional instruments for preparing Chicha such as the "batán" (a special stone mill used for milling the germinated corn kernels into a coarse flour) and the "chombas" (ceramic vessels where Chicha is fermented) while the "caporal" (typical glass that mimics the shape of "Kero" which was a ceramic or wooden vessel used to drink Chicha in the Inca period) is used for serving the final Chicha (see Additional file 1, B,C).

Chicha from Socabaya, Chiguata, and Uchumayo (Z3, Z4, and Z5, respectively) are made with Güiñapo from commercial origin which is generally made with commercial purple corn kernels (likely of varieties from other regions in Peru) and once germinated and dried, the final product might be mixed with Güiñapo from different local suppliers. This reveals that "picanterias" are increasing the use of commercial Güiñapo which is not always processed using neither native purple corn varieties nor standardized conditions leading to potential differences in Chicha flavor and texture. Producers from these zones sometimes use the traditional tools for Chicha preparation or combine the use of plastic or 
Table 1 Sampling locations and key points in the elaboration process of Chicha de Güiñapo in the Arequipa region

\begin{tabular}{|c|c|c|c|c|c|}
\hline Zone & Arequipa (Z1) & Characato (Z2) & Socabaya (Z3) & Chiguata (Z4) & Uchumayo (Z5) \\
\hline Latitude & -16.457194 & -16.464156 & -16.457194 & -16.402603 & -16.424996 \\
\hline Longitude & -71.543811 & -71.493390 & -71.543811 & -71.391579 & -71.663230 \\
\hline Name of the Picanteria & La Nueva Palomino & Charito & $\begin{array}{l}\text { Andenes del } \\
\text { Koricancha }\end{array}$ & Doña Leo & Picanteria-Bar Marilú \\
\hline Raw material & Purple corn & Purple corn & $\begin{array}{l}\text { Commercial } \\
\text { Güiñ̃apo' }\end{array}$ & $\begin{array}{l}\text { Commercial } \\
\text { Güiñ̃apo }\end{array}$ & $\begin{array}{l}\text { Commercial } \\
\text { Güiñapo' }\end{array}$ \\
\hline Germination & 15 days & 20 days & No & No & No \\
\hline Drying & 3 days & 5 days & No & No & No \\
\hline Milling & Yes & Yes & No & No & No \\
\hline Güiñapo/water rate (kg/L) & Not informed & $1 / 33$ & $1 / 20$ & $1 / 16$ & $1 / 18$ \\
\hline Boiling (h) & 3 & 1 & 1 & 1 & 3 \\
\hline Filtration & Yes & Yes & Yes & Yes & Yes \\
\hline Fermentation & $\begin{array}{l}\text { Overnight with } \\
\text { addition of sugar }\end{array}$ & $\begin{array}{l}\text { Overnight with } \\
\text { addition of sugar }\end{array}$ & $12 \mathrm{~h}$ & $12 \mathrm{~h}$ & $\begin{array}{l}4-5 \mathrm{~h} \text { with addition } \\
\text { of sugar }\end{array}$ \\
\hline Starter & $\begin{array}{l}\text { Chicha from the } \\
\text { previous day }\end{array}$ & $\begin{array}{l}\text { Chicha from the } \\
\text { previous day }\end{array}$ & $\begin{array}{l}\text { Chicha from the } \\
\text { previous day }\end{array}$ & $\begin{array}{l}\text { Chicha from the } \\
\text { previous day }\end{array}$ & $\begin{array}{l}\text { Chicha from the } \\
\text { previous day }\end{array}$ \\
\hline $\begin{array}{l}\text { Additional ingredients after } \\
\text { fermentation }\end{array}$ & Sugar ${ }^{4}$ & None $^{2}$ & Sugar ${ }^{3}$ & Sugar $^{3}$ & Sugar ${ }^{4}$ \\
\hline
\end{tabular}

${ }^{1}$ Milled and partially germinated purple corn kernels

${ }^{2}$ Sugar added at the beginning of the fermentation

${ }^{3}$ Sugar added at the end of the fermentation

${ }^{4}$ Sugar added at the beginning and the end of the fermentation

metal pots for the fermentation step (see Additional file $1, \mathrm{D}-\mathrm{F})$.

Both the boiling and fermentation times differ between the sampling locations. Since Chicha is made in artisanal conditions, it is most likely that these parameters are not exactly supervised, and therefore, it is difficult to determine their influence in the final quality and composition of Chicha. Overall, the time of fermentation ranges from 10 to $12 \mathrm{~h}$ with the addition of sugar at the beginning of the fermentation step (Z2), at the end of the process ( $Z 3$ and Z4), or both (Z1 and Z5) (Table 1). In contrast, the Chicha in Uchumayo (Z5) had the lowest fermentation time $(4-5 \mathrm{~h})$ which may explain its lowest contents in the total phenolic compounds and total monomeric anthocyanins as shown in Table 3. Differences concerning the type of raw material and the processing parameters would likely influence the bioactive composition and health-relevant functional properties of Chicha.

Chich $a$ is the most representative fermented beverage made from corn in the Andean region, but there are other important corn-based fermented products across Central and South America. In Mexico, a beverage called Pozol is produced based on the fermentation of both corn and cacao beans. Pozol production includes a direct boiling of these grains without a previous germination process. The fermentation time is also increased to around 12 days which increases the alcohol content in the beverage thus making its flavor quite different from
Chicha [16]. In Ecuador, Chicha is produced using yellow, white, or purple corn. The grains are left in water for a day, after which the germination time is set to around 13 days similarly as in the case of Chicha de Güiñapo [15].

\section{Physicochemical properties}

The physicochemical characteristics measured in Chicha samples from different origins are shown in Table 2 . The $\mathrm{pH}$ value ranged from 3.21 to 3.72 whereas the ethanol content $(\% \mathrm{v} / \mathrm{v})$ and the titratable acidity varied from 1.63 to 3.43 and from 0.23 to $0.36 \mathrm{~g}$ lactic acid/100 $\mathrm{mL}$, respectively. The Z5 Chicha showed the highest ethanol concentration among samples whereas Z1 had the highest acidity. The alcohol content showed a high variability (up to $67 \%$ for $\mathrm{Z} 4$ ) indicating differences in the fermentation time or other parameters such as the type and composition of the starter used in Chicha processing at different weeks. Likely, the starter used every time varies in microbiome composition and activity which in turn affects the final alcohol content. The soluble solids were overall similar among all Chicha samples ranging from 9.57 to $11.70{ }^{\circ}$ Brix and Z5 sample showed the lowest value. This sample also showed the lowest titratable acidity which may be associated to its lowest time of fermentation among the other samples (Table 1). 
Table 2 Physicochemical properties of Chicha de Güiñapo

\begin{tabular}{lcccr}
\hline Zone & $\mathrm{pH}$ & Ethanol (\%) & $\begin{array}{c}\text { Titratable acidity } \\
\text { (g lactic acid/100 mL) }\end{array}$ & ${ }^{\circ}$ Brix \\
\hline Z1 & $3.21 \pm 0.04$ & $2.30 \pm 1.32$ & $0.36 \pm 0.04$ & $11.70 \pm 1.57$ \\
Z2 & $3.43 \pm 0.11$ & $2.07 \pm 0.98$ & $0.31 \pm 0.03$ & $10.70 \pm 2.98$ \\
Z3 & $3.72 \pm 0.44$ & $1.67 \pm 0.25$ & $0.24 \pm 0.11$ & $11.47 \pm 0.99$ \\
Z4 & $3.39 \pm 0.08$ & $1.63 \pm 1.11$ & $0.30 \pm 0.04$ & $10.43 \pm 1.62$ \\
Z5 & $3.60 \pm 0.04$ & $3.43 \pm 1.45$ & $0.23 \pm 0.03$ & $9.57 \pm 0.93$ \\
\hline
\end{tabular}

No significant difference at $p<0.05$

Although no statistical differences were found in evaluated parameters, some Chicha samples such as Z3 and Z5 exhibited differences in terms of ethanol concentration, titratable acidity, and ${ }^{\circ}$ Brix. The processing parameters such as the type of raw material (corn or Güiñapo), fermentation time, the composition of the starter, and the use or not of sugar during and after the fermentation might explain observed differences. The standardization of the Chicha processing and the potential interaction of sugar with Chicha microbiome and its effect on physicochemical properties and bioactivity needs further research.

Other authors have reported similar physicochemical results for other corn-based fermented beverages. Barbosa et al. [15] have reported a $\mathrm{pH}$ value of 3.65, a mean titratable acidity of $0.24 \mathrm{~g}$ lactic acid $/ 100 \mathrm{~mL}$, and an average ethanol concentration of $2.16 \%$ when evaluating an Ecuadorian Chicha made with white, yellow, and purple corn. Nuraida et al. [24] found a pH value of 4.05 and a mean titrable acidity of $0.40 \mathrm{~g}$ lactic acid/100 g in Pozol samples after a 6-day fermentation period.

\section{Total phenolic content, anthocyanin content, and} antioxidant capacity

The total phenolic contents (TPC), the total monomeric anthocyanins (TMA), and the total anthocyanin contents (TAC) measured by UHPLC-DAD along with the antioxidant capacity assayed with two in vitro methods are shown in Table 3. No statistical differences were found among results based on the Chicha origin; however, certain variability was observed in the results of TPC, TMA, TAC, and the antioxidant capacity. The TPC varied from 28.09 to $41.79 \mathrm{mg}$ GAE/100 mL whereas the TMA and the TAC ranged from 16.81 to $31.09 \mathrm{mg}$ C3G/ $\mathrm{L}$ and from 39.45 to $63.16 \mathrm{mg} \mathrm{CC} / \mathrm{L}$, respectively. The Z2 sample had the highest values of TPC, TMA, and TAC among evaluated Chicha samples whereas Z5 sample had the lowest concentrations of these parameters.

A low variability in the antioxidant capacity results was observed among the Chicha samples from different origins. The Z2 sample had the highest antioxidant values with the ABTS and DPPH methods (235.78 and $131.94 \mu \mathrm{mol} \mathrm{TE} / 100 \mathrm{~mL}$, respectively). This sample also showed the highest TPC, TMA, and TAC values as stated previously. A significant positive correlation was found between the TPC and ABTS results, and between the TMA and TAC values, indicating that phenolic compounds from purple corn mostly anthocyanins or their microbial biotransformation-derived phenolic metabolites likely contributed to the antioxidant capacity in Chicha.

Flores-Calderon et al. [25] have reported similar TPC and TMA values (48 mg GAE/100 mL and $19 \mathrm{mg} \mathrm{C3G/}$ $\mathrm{L}$, respectively) as those reported in the current study when malt beers made with blue corn were evaluated. However, the same authors reported higher ABTS and DPPH antioxidant capacity results $(2600 \mu \mathrm{mol} \mathrm{TE} / 100$ $\mathrm{mL}$ and $4800 \mu \mathrm{mol} \mathrm{TE} / 100 \mathrm{~mL}$, respectively), which may

Table 3 Total phenolic content (TPC), total monomeric anthocyanin (TMA), total anthocyanin content (TAC), and antioxidant capacity by the ABTS and DPPH methods in Chicha

\begin{tabular}{lccccc}
\hline & $\mathrm{TPC}^{\dagger}(\mathrm{mg} \mathrm{GAE} / 100 \mathrm{~mL})$ & $\mathrm{TMA}^{* *}(\mathrm{mg} / \mathrm{L})^{\ddagger}$ & $\mathrm{TAC}(\mathrm{UHPLC})^{*}(\mathrm{mg} \mathrm{CC} / \mathrm{L})^{\ddagger}$ & $\mathrm{ABTS}^{\dagger}(\mu \mathrm{mol} \mathrm{TE} / 100 \mathrm{~mL})$ & $\mathrm{DPPH}(\mu \mathrm{mol} \mathrm{TE} / 100 \mathrm{~mL})$ \\
\hline$Z 1$ & $33.45 \pm 0.01$ & $18.37 \pm 2.59$ & $42.22 \pm 3.34$ & $187.21 \pm 7.89$ & $106.76 \pm 24.74$ \\
$Z 2$ & $41.79 \pm 0.08$ & $31.09 \pm 9.73$ & $63.16 \pm 13.59$ & $235.78 \pm 41.50$ & $131.94 \pm 14.77$ \\
$Z 3$ & $30.63 \pm 0.05$ & $25.73 \pm 8.95$ & $52.78 \pm 12.69$ & $177.07 \pm 26.18$ & $122.44 \pm 32.24$ \\
$Z 4$ & $35.54 \pm 0.06$ & $27.06 \pm 6.71$ & $57.31 \pm 9.07$ & $213.98 \pm 31.87$ & $120.99 \pm 32.24$ \\
$Z 5$ & $28.09 \pm 0.03$ & $16.81 \pm 6.07$ & $39.45 \pm 9.25$ & $203.28 \pm 80.09$ & $108.47 \pm 22.32$ \\
\hline
\end{tabular}

No significant difference at $p<0.05$

*Expressed as cyanidin chloride aglycon

**Expressed as cyanidin-3-glucoside equivalents.

${ }^{\dagger}$ Significant correlation (Pearson) between TPC and ABTS; $r=0.62$

${ }^{\ddagger}$ Significant correlation (Pearson) between TMA and TAC; $r=0.78$ 
be due to the longer fermentation time of malt beer likely associated to increasing biotransformation of molecules with antioxidant capacity compared to the fermentation time applied in Chicha samples evaluated in the current research (16 days versus 1 day) [25]. The fermentation process has been reported to improve the antioxidant capacity of different fermented foods and beverages through the biotransformation of polyphenols by lactic acid bacteria [26, 27]. In addition, TPC ranges from 30 to $35 \mathrm{mg}$ GAE/ $100 \mathrm{~mL}$ and in vitro antioxidant capacity values of 300 and $180 \mu \mathrm{mol} \mathrm{TE} / 100 \mathrm{~mL}$ have been found by Zou et al. [28] for a beverage made from persimmon (Diospyros kaki) vinegar fermentation process for 2 weeks. These values are comparable to ranges found in the current research.

\section{Alpha-glucosidase enzyme inhibitory activity}

The $\alpha$-glucosidase inhibitory activity was determined for the undiluted and 1/2,1/5, and 1/10 diluted Chicha samples, and the different doses were expressed as milligrams of GAE $/ \mathrm{mL}$ of Chicha. According to Fig. 5, all samples inhibited the $\alpha$-glucosidase enzyme in a dosedependent trend. No significant differences $(p<0.05)$ were found among the $\alpha$-glucosidase inhibitory activity results for the undiluted Chicha and the 1/10 dilution. $\mathrm{Z} 2$ and Z4 samples showed the highest inhibitory activity $(74.26-75.73 \%$ and $44.47-52.51 \%$, at $1 / 2$ and $1 / 5 \mathrm{di}-$ lutions equivalent to 0.034 and $0.014 \mathrm{mg} \mathrm{GAE} / \mathrm{mL}$, respectively).
The inhibition of $\alpha$-glucosidase enzyme was significantly correlated to the TPC at all assayed dilutions $(r=0.6-0.75, p<0.05)$ indicating that phenolic compounds likely reflecting anthocyanins may be related to observed bioactivity. Polyphenols are known to have a high antioxidant capacity and a medium to high in vitro $\alpha$-glucosidase and $\alpha$-amylase inhibitory activity [29]. Several studies have found a high correlation between the TMA or specific types of anthocyanins with the inhibition of $\alpha$-glucosidase and other enzymes relevant for the metabolism of polysaccharides [30, 31].

Other phenolic or non-phenolic compounds likely released or metabolized during the mixed lactic acid bacteria and yeast-based fermentation in Chicha may have also contributed to the high $\alpha$-glucosidase inhibition shown in the current investigation, but more research is needed to elucidate this possibility. Simamora et al. [32] have reported $\alpha$-glucosidase inhibitory activity of $65.53 \pm 0.75 \%$ for a 100-day fermented-based juice made with Morinda citrifolia at a $0.035 \mathrm{mg} \mathrm{GAE} / \mathrm{mL}$ dose. Chicha samples with lower fermentation time $(12 \mathrm{~h})$ had comparable ranges of inhibition (53.31-75.73\%) at a similar sample dose (0.034 mg GAE/mL).

\section{Alpha-amylase enzyme inhibitory activity}

The results of the $\alpha$-amylase inhibitory activity determined at different dilutions of Chicha samples are shown in Fig. 6. The $\mathrm{Z} 2$ undiluted sample showed the

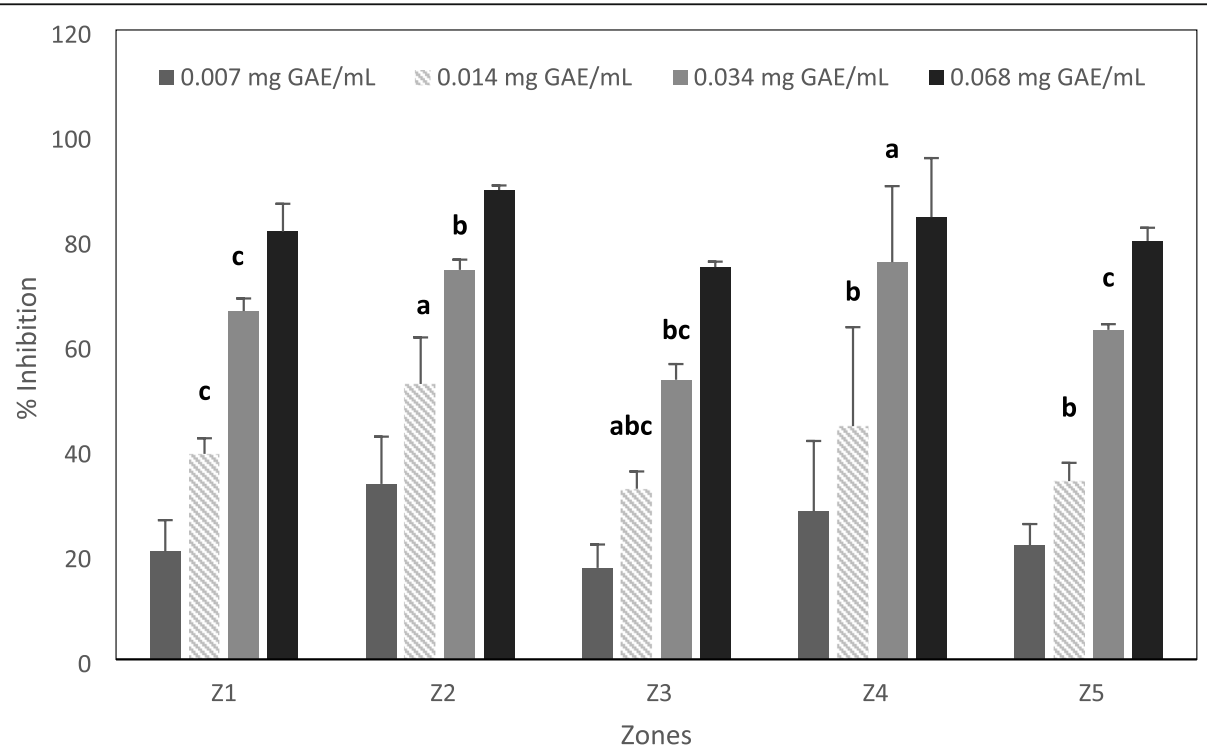

Fig. 5 Dose-dependent $(0,1 / 2,1 / 5$, and $1 / 10$ dilutions corresponding to $0.068,0.034,0.014$, and $0.007 \mathrm{mg} \mathrm{GAE} / \mathrm{mL}$ doses, respectively) response in a-glucosidase inhibitory activity (\%) of Chicha from five different locations in Arequipa. Different lower-case letters in bars with similar pattern indicate significant differences at $p<0.05$ 


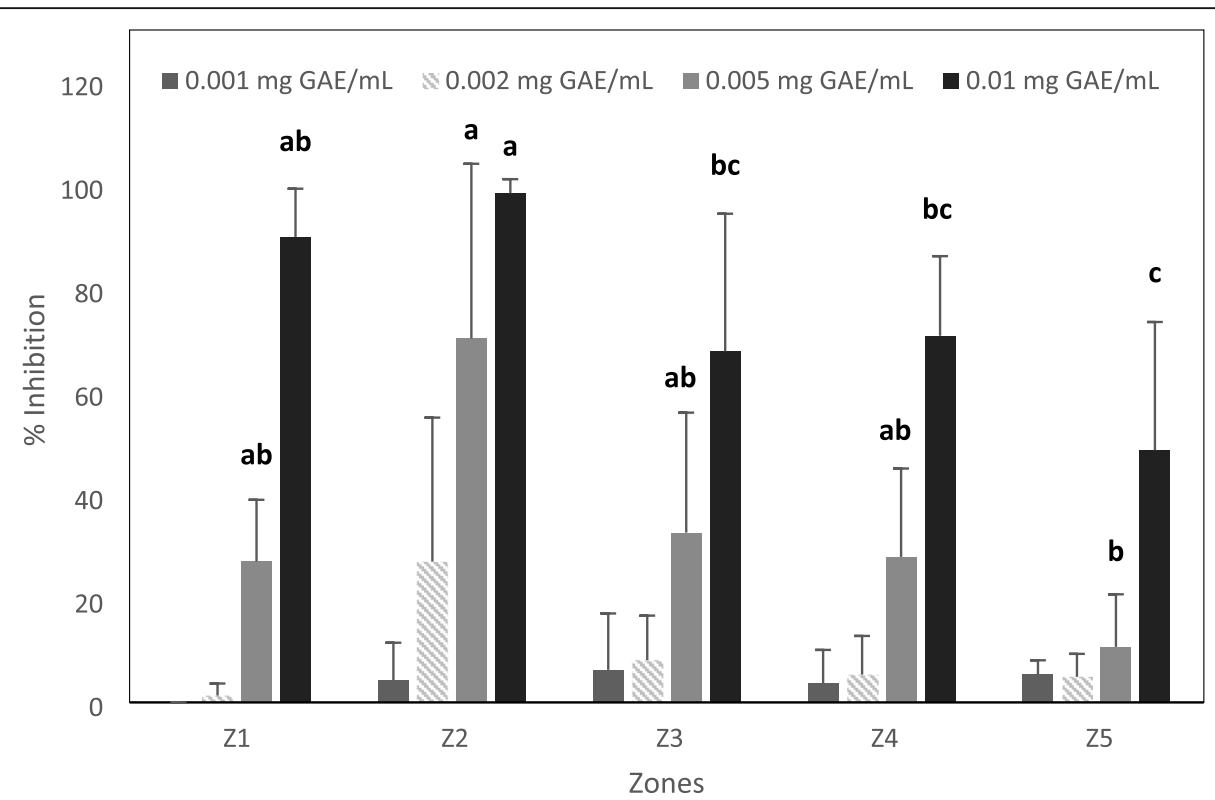

Fig. 6 Dose-dependent response (0,1/2,1/5, and 1/10 dilutions corresponding to 0.01, 0.005, 0.002, and $0.001 \mathrm{mg} G A E / \mathrm{mL}$ doses, respectively) response in a-amylase inhibitory activity (\%) of Chicha from five different locations in Arequipa. Different lower-case letters in bars with similar pattern represent significant differences at $p<0.05$

highest $\alpha$-amylase inhibitory activity (98.41\%) followed by Z1 (89.99\%). At a lower sample dose $(0.005 \mathrm{mg} \mathrm{GAE/}$ $\mathrm{mL}), \mathrm{Z} 2$ sample also exhibited the highest inhibition among evaluated samples. Pearson coefficients revealed a positive correlation between the TPC levels and the $\alpha$ amylase inhibitory activity at $1 / 2$ and $1 / 5$ dilutions $(r=$ 0.84 and $r=0.70, p<0.05$, respectively) indicating that anthocyanins and likely other fermentation-derived phenolic compounds might be associated with the inhibition of $\alpha$-amylase.

Johnson et al. [33] have reported a high $\alpha$-amylase inhibitory activity $(92.21 \%$ at a dose of $0.59 \mathrm{mg}$ GAE/ $\mathrm{mL}$ ) for yeast fermented berry juice with high anthocyanin contents (up to $71.4 \pm 10.4 \mathrm{mg}$ C3G/L). Ranges from 35 to $38 \%$ and from 0 to $25 \%$ have been reported in undiluted and partially diluted fermented beverages such as tea and wine which are lower than results reported here [34]. This may be related to differences in the phenolic profile and the type of processing associated with tea and wine compared to Chicha.

\section{Conclusion}

The traditional knowledge based on historical perspectives of the ethnic beverage Chicha de Güiñapo is being preserved in evaluated districts of Arequipa (Peru). Linking historical perspectives this study found some differences in the type of raw material and processing parameters depending on the geographical localization of picanterias. In terms of contemporary chemical analysis of physicochemical parameters, the phenolic contents and the in vitro antioxidant capacity have not been affected by such processing differences; however, the inhibition of the health-relevant $\alpha$-amylase and $\alpha$-glucosidase enzymes was significantly influenced and correlated to the TPC. The Z2 sample which followed the most traditional ethnic production process showed the highest potential for health associated hyperglycemia management. The current study shows for the first time the health-relevant potential of the traditional ethnic Peruvian purple corn-based fermented beverage Chicha de Güiñapo. Further follow-up studies are being conducted from the foundations of this research to understand the changes in phenolic profiles and probiotic microbiome likely developed during the fermentation of Chicha for current health applications which in turn would help to preserve the historical perspectives and ethnic knowledge of its processing and cultural relevance among people from the Andean region.

\section{Supplementary information}

Supplementary information accompanies this paper at https://doi.org/10. 1186/s42779-020-00063-3.

Additional file 1. Supplementary figures. Figure A: Chicha made from different cereals in Peru. Figure B: Picanteria of Zone 1. Figure C:

Picanteria of Zone 2. Figure D: Picanteria of Zone 3. Figure E: Picanteria of Zone 4. Figure F: Picanteria of Zone 5. 


\section{Acknowledgements}

No acknowledgments to declare.

\section{Authors' contributions}

Diego Vargas-Yana drafted the paper and together with Brigitte AguilarMorón and Nelly Pezo-Torres conducted the experimental work. Lena Gálvez Ranilla and Kalidas Shetty designed the study, edited the paper, and critically reviewed the manuscript. All authors contributed as members of the research group and approved the manuscript.

\section{Funding}

This study was supported by the Vice-presidency of Research of Universidad Catolica de Santa Maria (Arequipa-Peru) under the contract N² 25789-R-2018.

\section{Availability of data and materials}

All data and materials are available and presented in the manuscript.

\section{Competing interests}

The authors declare that they have no competing interests.

\section{Author details}

${ }^{1}$ Laboratory of Research in Food Science, Universidad Catolica de Santa Maria, Urb. San José s/n Umacollo, Arequipa, Peru. ²Department of Plant Sciences, North Dakota State University, Fargo, ND 58108, USA.

Received: 25 March 2020 Accepted: 12 August 2020

\section{Published online: 22 September 2020}

\section{References}

1. Ruíz RA. In: Barrera Delgado M, editor. La gran cocina mestiza de Arequipa. 3rd ed. Arequipa: Tambo de Papel Editores; 2017.

2. Álvarez Novoa I, Cayllahua Muñoz G, Ramírez Angulo E, Arquíñigo VR. Picanterías y chicherías del Perú Patrimonio Cultural de la Nación. 1st ed. Iglesias J, editor. Lima: Universidad San Martín de Porres. Fondo Editorial; 2017.

3. Horkheimer H. Alimentación y obtención de alimentos en el Perú prehispánico Lima: Instituto Nacional de Cultura; 2004.

4. Burger RL, Van Der Merwe NJ. Maize and the origin of highland Chavín civilization: an isotopic perspective. Am Anthropol. 1990:92(1):85-95.

5. Candia GA. La cerámica prehispánica del Qosqo. 1st ed. Municipalidad del Cusco: Cusco; 1996.

6. Neira Avedaño M, Galdos Rodriguez G, Medina Malaga A. Paz Soldan Quiroz E, Carpio Muñoz JG. Historia general de Arequipa. Arequipa: Fundación M.J. Bustamante de la Fuente; 1990

7. Goldstein PS. From stew-eaters to maize-drinkers the Chicha economy and Tiwanaku. In: Bray TL, editor. The archaeology and politics of food and feasting in early states and empires. New York: Springer US; 2003. p. $143-72$.

8. Merriman CP. Machu Picchu: Unveiling the mystery of the Incas. Social Studies curriculum. New Haven: Yale University, Department of Public Education; 2003

9. Castillo Butters LJ. Los rituales Mochica de la muerte. In: Makowski K, editor. Los dioses del antiguo Perú. Lima: Banco de Crédito del Perú; 2000. p. 103-35

10. Jennings J. La chichera y el patrón: Chicha and the energetic of feasting in the prehistoric Andes. AP3A. 2005;14:241-59.

11. Instituto Nacional de Estadística e Informática INEI. Conociendo Arequipa. 1st ed. Lima: INEl; 2000. Map of Arequipa. p. 11.

12. Banco Central de Reserva del Perú BCRP. Encuentro económico: Informe Económico y Social Región Arequipa. 1st ed. Arequipa: BCRP; 2016. Political map of Arequipa. p. 10.

13. Map of Arequipa [Map on the Internet]. Arequipa: Google Maps; $c 2020$ [cited 2020 May 22]. Available from: https://www.google.com/maps/place/ Arequipa/@-16.3669535,-71.5430004,9.75z/data=!4m5!3m4!1s0x914235f9a713 829f:0xf17a9689bf1605a0!8m2!3d-16.409032!4d-71.5374763.

14. Mendoza ML, Neef A, Vignolo G, Belloch C. Yeast diversity during the fermentation of Andean chicha: a comparison of high-throughput sequencing and culture-dependent approaches. Food Microbiol. 2017 $67: 1-10$.

15. Barbosa Piló F, Carbajal-Barriga E, Guamán-Burneo M, Portero-Barahona P, Morato Dias A, Freitas L, et al. Saccharomyces cerevisiae populations and other yeasts associated with indigenous beers (chicha) of Ecuador. Braz J Microbiol. 2018:49(4):808-15.

16. Jiménez Vera R, González Cortés N, Magaña Contreras A, Corona CA. Microbiological and sensory evaluation of fermented white pozol, with cacao (Theobroma cacao) and coconut (Cocos nucifera). Rev Venez Cienc Tecnol Aliment. 2010;1(1):70-80.

17. AOAC International. Official methods of analysis of AOAC International. 20th Edition ed. W. Latimer GJ, editor. Rockville: AOAC International; 2016.

18. Singleton VL, Rossi JA. Colorimetry of total phenolics with phosphomolybdic-phosphotungstic acid reagents. Am J Enol Vitic. 1965;16: $144-58$

19. Lee J, Durst RW, Wrolstad RE. Determination of total monomeric anthocyanin pigment content of fruit juices, beverages, natural colorants, and wines by the $\mathrm{pH}$ differential method: Collaborative Study. J AOAC Int. 2005:88(5):1269-78.

20. Rodriguez-Saona LE, Wrolstad RE. Extraction, isolation, and purification of anthocyanins. Curr Protoc Food Anal Chem. 2001;0(1):F1.1.1-F1.1.11.

21. Pérez-Jiménez J, Saura-Calixto F. Effect of solvent and certain food constituents on different antioxidant capacity assays. Food Res Int. 2006; 39(7):791-800

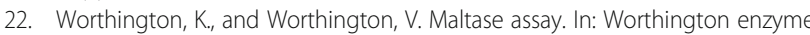
manual. 2011. http://www.worthington-biochem.com/MALT/assay.html. Accessed 28 Aug 2019

23. Worthington, K., and Worthington, V. Amylase, Alpha assay. In: Worthington enzyme manual. 2011. http://www.worthington-biochem.com/AA/assay. html. Accessed 28 Aug 2019.

24. Nuraida L, Wacher MC, Owens JD. Microbiology of pozol, a Mexican fermented maize dough. World J Microb Biot. 1995;11:567-671.

25. Flores-Calderón AMD, Luna H, Escalona-Buendía HB, Verde-Calvo JR. Chemical characterization and antioxidant capacity in blue corn (Zea mays L) malt beers. J Inst Brew. 2017:123(4):506-18.

26. Li Z, Teng J, Yilu L, Hu X, Zhao Y, Wang M. Enhanced antioxidant activity for apple juice fermented with Lactobacillus plantarum ATCC14917. Molecules. 2018;24(1):51

27. Hur SJ, Lee SY, Kim YC, Choi I, Kim GB. Effect of fermentation on the antioxidant activity in plant-based foods. Food Chem. 2014;160(1): 346-56.

28. Zou B, Wu J, Yu Y, Xiao G, Xu Y. Evolution of the antioxidant capacity and phenolic contents of persimmon during fermentation. Food Sci Biotechnol. 2017;26(3):563-71.

29. Rasaouli H, Hosseini-Ghazvini SM, Adibi H, Khodarahmi R. Differential aamylase/a-glucosidase inhibitory activities of plant-derived phenolic compounds: a virtual screening perspective for the treatment of obesity and diabetes. Food Funct. 2017:8(5):1942-54.

30. Zhang J, Xiao J, Giampieri F, Forbes-Hernandez TY, Gasparrini M, Afrin S, et al. Inhibitory effects of anthocyanins on a-glucosidase activity. J Berry Res. 2018;9(4):1-15.

31. Ranilla LG, Huamán-Alvino C, Flores-Báez O, Aquino-Méndez EM, Chirinos R, Campos D, et al. Evaluation of phenolic antioxidant-linked in vitro bioactivity of Peruvian corn (Zea mays L.) diversity targeting for potential management of hyperglycemia and obesity. J Food Sci Technol. 2019;56(6): 2909-24.

32. Simmamora A, Santoso AW, Timotius KH. a-Glucosidase inhibitory effect of fermented fruit juice of Morindacitrifolia L. and combination effect with acarbose. Curr Res Nutr Food Sci. 2019:7(1):218-26.

33. Johnson MH, Lucius A, Meyer T, Gonzalez de Mejia E. Cultivar evaluation and effect of fermentation on antioxidant capacity and in vitro inhibition of a-amylase and a-glucosidase by Highbush Blueberry (Vaccinium corombosum). J Agric Food Chem. 2011;59(16): 8923-30.

34. Kwon $\mathrm{Yl}$, Apostolidis $\mathrm{E}$, Shetty K. Inhibitory potential of wine and tea against a-amylase and a-glucosidase for management of hyperglycemia linked to type 2 Diabetes. J Food Biochem. 2008:32(1):15-31.

\section{Publisher's Note}

Springer Nature remains neutral with regard to jurisdictional claims in published maps and institutional affiliations. 